\title{
KASUS DISTOKIA PADA SAPI POTONG DI KECAMATAN KUNIR KABUPATEN LUMAJANG TAHUN 2015 DAN 2016
}

\section{THE CASE OF DYSTOCIA IN BEEF CATLLE IN KECAMATAN KUNIR KABUPATEN LUMAJANG YEARS 2015 AND 2016}

\author{
Rosiana Febrianila ${ }^{1)}$,Widya Paramita L. ${ }^{2)}$, Tjuk Imam R. ${ }^{3)}$, Imam Mustofa ${ }^{4)}$, \\ Erma Safitri' ${ }^{5)}$, Herry Agoes Hermadi') \\ ${ }^{1)}$ Student, ${ }^{2)}$ Departement of Husbandry, ${ }^{3,4,5,6)}$ Departement of Reproduction \\ Veterinary Medicine Faculty Airlangga University \\ ochi.rf93@gmail.com
}

\begin{abstract}
Dystocia defined as difficulty of birth. Catlle that experienced dystocia characterized by extended processing time of birth, difficult, and impossible to do without help of human stem. This study aimed to determine the number of and causative factor of dystocia in beef cattle in Kecamatan Kunir Kabupaten Lumajang. Data acquisition used primary data and secondary data. Primary data was obtained from direct observations about management of maintenance, then interviewed the farmers in Kecamatan Kunir. Secondary data was data obtained from the recording belongs to animal health technical officer. The results showed that the prevalence of dystocia in Kecamatan Kunir Kabupaten Lumajang as many as 63 cases or 11,6 \% of 543 birth. The result of the research is analyzed using chi square $\left(\chi^{2}\right)$ method on SPSS 20.0 program and risk factors that increase the incident of dystocia were IB semen which greater than the catlle site, the position of the foetus and inertis uteri can resulting in weakness of the catlle at the age of older and more likely to give birth.
\end{abstract}

Key Words: dystocia, beef catlle.

\section{Pendahuluan}

Gangguan reproduksi pada sapi dapat diakibatkan oleh berbagai faktor, diantaranya adalah yang bersifat tidak menular (non infectious agent) dan yang bersifat menular (infectious agent). Khusus untuk gangguan reproduksi yang diakibatkan oleh agen infeksius atau penyakit menular, menurut Bearden and Fuquay (2004) menerangkan bahwa penyakit reproduksi menular dapat mengakibatkan abortus, pyometra, endometritis, kematian embrio, kemajiran, retensi plasenta, kerusakan syaraf pusat dari fetus, sterilitas pada pejantan. Dengan demikian akibatnya gangguan reproduksi pada ternak akan merugikan para peternak dan secara nasional tentunya akan rnemperlambat laju peningkatan populasi ternak di dalam negeri. Peningkatan populasi ternak sapi nasional yang lamban mengakibatkan pemerintah harus melakukan impor secara terus-menerus untuk mencukupi kebutuhan konsumsi dalam negeri (Riady, 2006).

Gangguan reproduksi yang umum terjadi pada sapi diantaranya: (1) retensio sekundinarium (ari-ari tidak keluar), (2) distokia (kesulitan melahirkan) (3) abortus (keguguran), dan (4) kelahiran prematur/sebelum waktunya (Ratnawati dkk., 2007)

Distokia adalah kesukaran dalam proses kelahiran yang diakibatkan oleh faktor induk atau fetus, sehingga untuk terjadinya kelahiran diperlukan bantuan manusia. Penyebab kesukaran dalam proses kelahiran pada sapi meliputi tiga faktor utama yaitu kekurangan tenaga pada induk untuk mengeluarkan fetus, adanya gangguan pada jalan kelahiran induk, dan adanya kelainan pada fetusnya. Kejadian distokia secara umum terjadi pada sapi yang pertama kali melahirkan (premipara) daripada sapi yang sudah beberapa kali melahirkan (pluripara) (Mahaputra dkk., 2011).

Penelitian ini dilakukan untuk mengetahui kasus distokia jumlah dan faktorfaktor yang menyebabkan kasus distokia yang terjadi pada sapi potong di Kecamatan 
Kunir Kabupaten Lumajang Tahun 2015 dan 2016

\section{Materi dan Metode Penelitian}

Penelitian ini dilaksanakan di wilayah kerja Petugas Teknis Kesehatan Hewan Kecamatan Kunir Kabupaten Lumajang. Penelitian dilaksanakan pada bulan Oktober - Desember 2016. Materi yang digunakan dalam penelitian ini adalah data catatan sapi betina yang mengalami kasus distokia dari seluruh kasus-kasus gangguan reproduksi pada tahun 2015 dan 2016 Metode yang digunakan dalam penelitian ini adalah metode deskriptif. Data yang diambil berupa data primer dan data sekunder. Data primer diperoleh dari pengamatan secara langsung mengenai manajemen pemeliharaan, kemudian dilakukan wawancara pada peternak

\section{Analisis Data}

Data yang sudah terkumpul disajikan dalam bentuk tabel dan hasilnya merupakan data dalam bentuk deskriptif. Selanjutnya untuk menganalisis faktor-faktor penyebab kasus distokia menggunakan analisis statistik menggunakan Chi Square.

\section{Hasil dan Pembahasan}

Jumlah kasus distokia pada sapi potong yang terjadi selama dua tahun 2015 dan 2016 di Kecamatan Kunir Kabupaten Lumajang dapat dilihat pada Tabel 1 .

Berdasarkan Tabel 1. kasus distokia pada sapi potong di tahun 2015 menunjukkan angka yang lebih tinggi yaitu sebanyak 38 kasus atau sebesar 12,4\% dari pada kasus distokia pada sapi potong di tahun 2016 yang berjumlah 25 kasus atau sebesar 10,6\% dari seluruh kasus distokia. Jumlah kelahiran dari dua tahun tersebut menunjukkan angka 543 dengan 63 kasus dan persentase sebanyak 11,6\% dari seluruh kasus distokia. Data eutokia pada sapi potong di tahun 2015 sebanyak 269 atau sebanyak $87,6 \%$, sedangkan pada tahun 2016 sebanyak 211 atau sebesar $89,4 \%$ dan jumlah angka eutokia sebanyak 480 atau sebesar $88,4 \%$ dari seluruh angka kelahiran.

\section{Faktor-faktor yang Menyebabkan Kasus Distokia}

Menurut Toelihere (1985) kejadian distokia yang diakibatkan oleh faktor induk dapat disebabkan oleh berbagai keadaan. Keadaan tersebut meliputi bangsa, periode kelahiran, jumlah pakan, pergerakan tubuh induk (exercise) di luar kandang, gangguan reproduksi yang pernah diderita dan trauma saat kebuntingan. Faktor fetus yang berpengaruh terhadap kasus distokia meliputi ukuran fetus, jenis kelamin, kondisi fetus, dan letak fokus.

Data tentang pengaruh bangsa induk sapi terhadap kasus distokia pada sapi potong di Kecamatan Kunir Kabupaten Lumajang yang menggunakan analisis statistik chi-square adalah 0,468 >0,05 maka dapat disimpulkan bahwa H0 diterima, yang artinya tidak terdapat hubungan yang signifikan. Diduga pengaruh distokia untuk bangsa induk sapi adalah dari semen pejantan yang di IBkan, misalnya seperti sapi PO diberi semen sapi Limuosin maka akan terjadi distokia.

Data tentang pengaruh umur induk sapi terhadap kasus distokiapada sapi potong di kecamatan Kunir Kabupaten Lumajang yang menggunakan analisis statistik chisquare adalah $0,955>0,05$ maka dapat disimpulkan bahwa H0 diterima, yang artinya tidak terdapat hubungan yang signifikan. Umur induk berkaitan dengan dewasa kelamin pada induk. Jika induk masih berupa sapi dara kemungkinan untuk terjadinya distokia lebih tinggi karena umurnya masih terlalu muda. Hal ini disebabkan karena pada sapi betina yang masih muda ukuran rongga pelvis masih terlalu kecil sehingga jika dipaksakan untuk bunting saat melahirkan akan menyebabkan terjadinya fraktur (Jackson, 2007).

Tabel 1. Jumlah kasus distokia pada sapi potong di Kecamatan Kunir Kabupaten Lumajang

\begin{tabular}{cccc}
\hline Tahun & Kelahiran & Distokia & Eutokia \\
\hline 2015 & 307 & $38(12,4 \%)$ & $269(87,6 \%)$ \\
2016 & 236 & $25(10,6 \%)$ & $211(89,4 \%)$ \\
Jumlah & 543 & $63(11,6 \%)$ & $480(88,4 \%)$ \\
\hline
\end{tabular}


Data tentang pengaruh periode kelahiran terhadap kasus distokiapada sapi potong di kecamatan Kunir Kabupaten Lumajang yang menggunakan analisis statistik chi-square adalah $0,898>0,05$ maka dapat disimpulkan bahwa H0 diterima, yang artinya tidak terdapat hubungan yang signifikan. Menurut Hafez (2000) menyatakan bahwa sebanyak $30 \%$ sampai $60 \%$ kasus distokia terjadi pada kelahiran pertama, $8 \%$ sampai $25 \%$ pada kelahiran kedua, dan $2 \%$ sampai $8 \%$ pada kelahiran ketiga atau lebih. Distokia lebih umum terjadi pada sapi yang pertama kali melahirkan (premipara) daripada sapi yang sudah beberapa kali melahirkan (pluripara). Hal tersebut diakibatkan karena adanya regangan saluran kelahiran yang belum pernah dilewati oleh fetus. Inertia Uteri Sekunder merupakan inertia dari pengeluaran fetus dan keberhasilannya adalah penting daripada penyebab distokia (Mahaputra dkk., 2011).

Data tentang pengaruh pergerakan terhadap kasus distokiapada sapi potong di kecamatan Kunir Kabupaten Lumajang yang menggunakan analisis statistik chisquare adalah 0,470 > 0,05 maka dapat disimpulkan bahwa H0 diterima, yang artinya tidak terdapat hubungan yang signifikan. Faktor pergerakan yang berpengaruh pada kasus distokia diduga penyebabnya adalah inertia uteri pada induk sehingga induk kekurangan kontraksi saat melahirkan.

Data tentang pengaruh pakan terhadap kasus distokiapada sapi potong di kecamatan Kunir Kabupaten Lumajang yang menggunakan analisis statistik chi-square adalah 0,670>0,05 maka dapat disimpulkan bahwa H0 diterima, yang artinya tidak terdapat hubungan yang signifikan. Pemberian pakan yang berlebihan selama kebuntingan juga dapat menyebabkan distokia, hal ini disebabkan terjadinya penumpukan lemak yang berlebihan di daerah pelvis dan dapat mempersempit jalannya kelahiran sehingga mengakibatkan kesulitan saat melahirkan. Pemberian pakan yang kurang selama kebuntingan juga dapat menyebabkan distokia, hal ini induk kekurangan tenaga saat kontraksi (McDonald, 2010).

Data tentang pengaruh jenis kelamin fetus terhadap kasus distokiapada sapi potong di kecamatan Kunir Kabupaten Lu- majang yang menggunakan analisis statistik chi-square adalah 0,716 >0,05 maka dapat disimpulkan bahwa H0 diterima, yang artinya tidak terdapat hubungan yang signifikan. Menurut Ensmingers (1987) menyatakan bahwa fetus jantan mempunyai berat lahir lebih tinggi 2,3 kg sampai 3,2 kg daripada fetus betina. Fetus jantan juga mengalami masa kelahiran lebih panjang sekitar satu sampai dua hari disbanding dengan fetus betina. Menurut Keane dan Drennan (1990) yang dikutip oleh Prasojo., dkk (2010) pada sapi potong, tingkat pertumbuhan dan efisiensi produksi lebih tinggi pada ternak jantan dibandingkan betina.

Data tentang pengaruh ukuran fetus terhadap kasus distokiapada sapi potong di kecamatan Kunir Kabupaten Lumajang yang menggunakan analisis statistik chisquare adalah 0,604>0,05 maka dapat disimpulkan bahwa H0 diterima, yang artinya tidak terdapat hubungan yang signifikan. Faktor ukuran fetus pada penelitian ini tidak diketahui semen pejantan yang diberikan saat IB, apabila dari pejantan unggul yang lebih besar daripada induk pasti akan mengakibatkan distokia.

\section{Kesimpulan}

Jumlah kasus distokia pada sapi potong di Kecamatan Kunir Kabupaten Lumajang adalah sebanyak 63 kasus atau sebesar 11,6 $\%$ dari 543 kelahiran. Faktor yang disebutkan dalam naskah dengan hasil analisis chi-square adalah tidak berbeda nyata, jadi faktor lain yang berpengaruh adalah semen pejantan IB yang lebih besar dari induk, situs kedudukan fetus, dan inertia uteri yang bisa mengakibatkan kelemahan induk pada umur lebih tua dan lebih sering melahirkan.

\section{Daftar Pustaka}

Bearden, J. H. and Fuquay, J. W. 2004. Applied Animal Reproduction. 3rd ed. Prentice Hall. Englewood Cliffs. New Jersey. 108.

Ensmingers, M. E. 1987. Beef Cattle Science. 6th ed. The Interstate Printer and Publisher Inc. Danville Illionis. 190-219.

Hafez, E. S. E. 2000. Reproduction in Farm Animals. 7th ed. Kiawah Island. South Carolina USA. 340-341, 464465. 
Jackson, P. G. G. 2007. Handbook of Veterinery Obstetrics. Philadelphia. Elsevier Saunder Company. 25-30.

Keane M.G. and Drennan M.J. 1990. Comparison Of Growth And Carcas Composition Of Heifers In Three Production Systems And Steers And Effects Of Implantation With Anabolic Agents. Irish J Agric Res. 29:1-13.

Mahaputra, L., Mustofa, I., Utama, S. , Restiadi, T. I., Mulyati, S. 2011. Buku Ajar Ilmu Kebidanan Veteriner. Fakultas Kedokteran Hewan. Surabaya: Airlangga University Press. 59-79, 98-101.

McDonald, P. 2010. Animal Nutrition. Formerly Reader in Agricultural Biochemistry, University of Edinburgh, and Head of the Department of Agricultural Biochemistry, Edinburgh School of Agriculture. 430431 .
Prasojo, G., Arifiantini, I., dan Mohamad, K. 2010. Korelasi Antara Lama Kebuntingan Bobot Lahir dan Jenis Kelamin Pedet Hasil Inseminasi Buatan pada Sapi Bali. Jurnal Veteriner Maret 2010. 11(1) : 41-45.

Ratnawati, D., Pratiwi W. C., dan Lukman A. S. 2007. Penanganan Gangguan Reproduksi pada Sapi Potong. Pusat Penelitian dan Pengembangan Peternakan. Grati, Pasuruan. 3-4, 21-23.

Riady, M. 2006. Implementasi Program Menuju Swasembada Daging 2010. Strategi dan Kendala. Seminar Nasional Teknologi Peternakan dan Veteriner. Hal. 23-24.

Toelihere, M. R. 1985. Ilmu Kebidanan pada Ternak Sapi dan Kerbau. Universitas Indonesia Press. 132-186. 